\title{
Silver Birch Pollen IgA Measurement
}

National Cancer Institute

\section{Source}

National Cancer Institute. Siver Birch Pollen IgA Measurement. NCI Thesaurus. Code C130077.

A measurement of the silver birch pollen IgA in a biological specimen. 